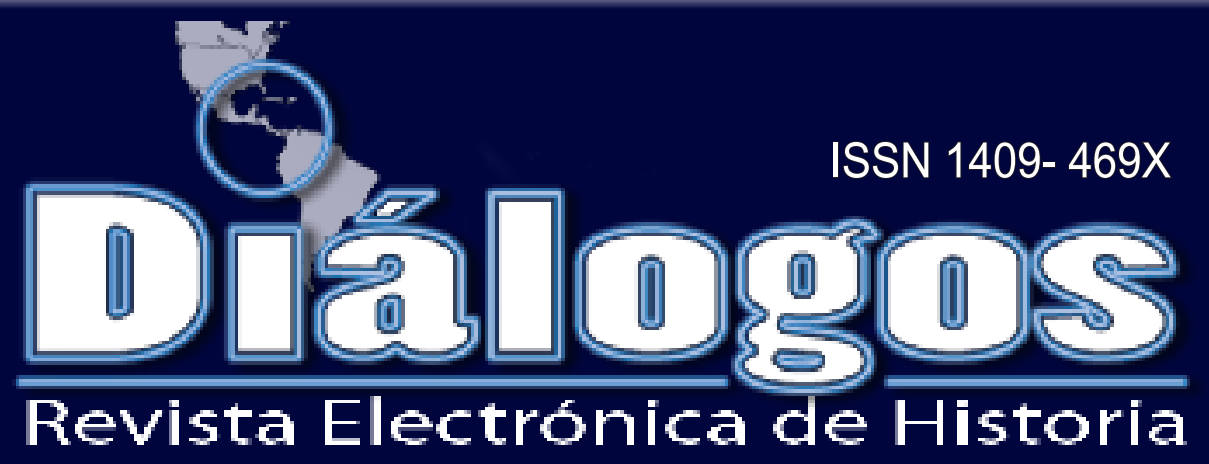

Escuela de Historia. Universidad de Costa Rica Vol. 13 No. 1 Febrero - Agosto 2012

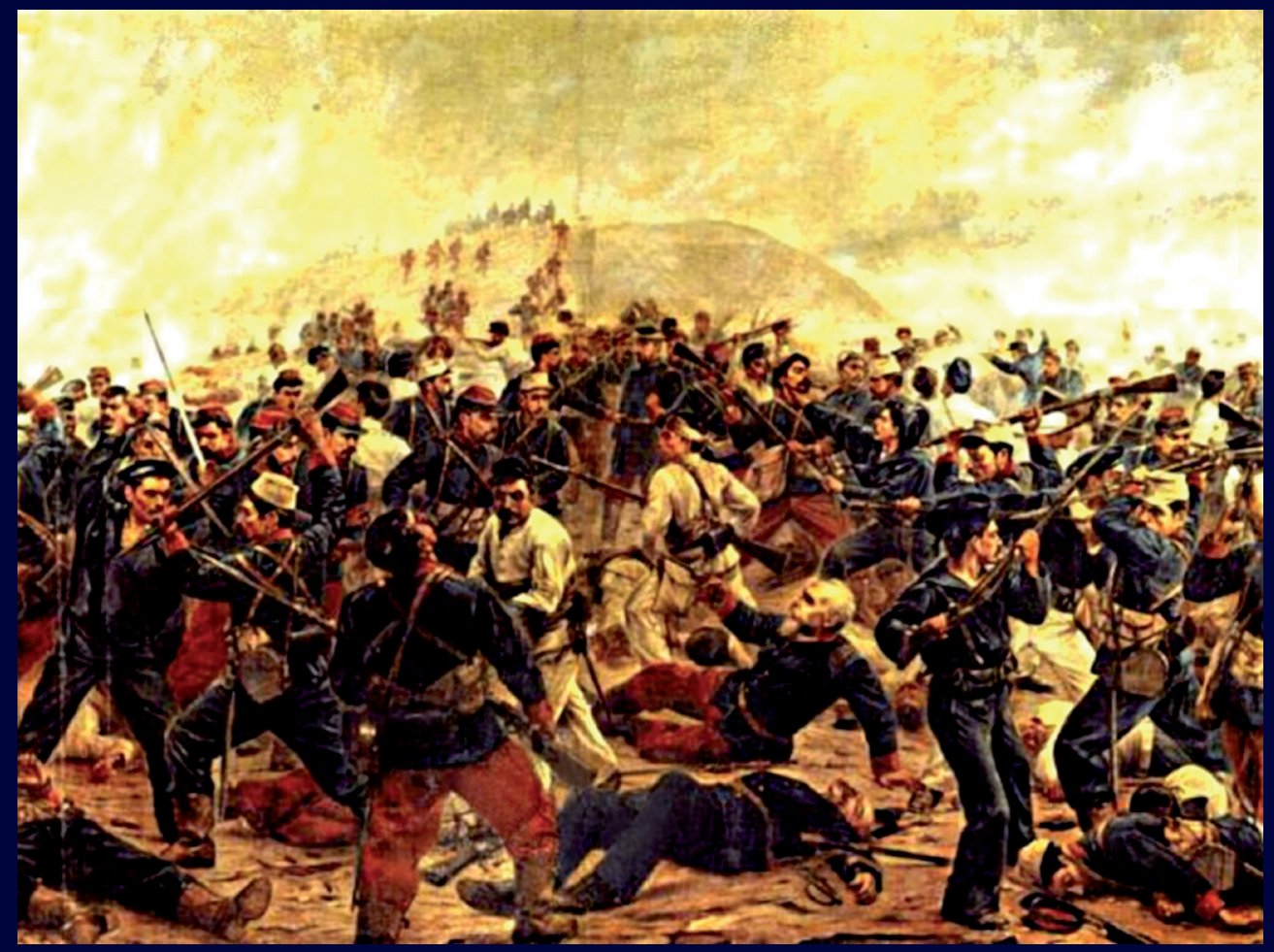

HISTORIA, CIUDAD Y FILOSOFÍA LATINOAMERICANA EN JOSÉ LUIS ROMERO

Alejandro Fielbaum S.

Director de la Revista: Dr. Juan José Marín Hernández juan.marinhernandez@ucr.ac.cr

Editor académico: Dr. Ronny Viales Hurtado - ronny.viales@ucr.ac.cr

Editor técnico: M.Sc. Marcela Quirós G. - marcela.quiros@ucr.ac.cr Asistente: Cindy Chaves U. http://historia.fcs.ucr.ac.cr/dialogos.htm 


\section{Miembros del Consejo Editorial:}

Dr. Juan José Marín Hernández, Catedrático. Director del Centro de Investigaciones Históricas de América Central. Universidad de Costa Rica.

Dr. Ronny Viales Hurtado. Catedrático. Historia Económica y Social. Universidad de Costa Rica. Director de la Escuela de Historia. ronny.viales@ucr.ac.cr

Dr. Guillermo Carvajal. Geografía Humana. Universidad de Costa Rica.

MSc. Francisco Enríquez. Historia Social. Universidad de Costa Rica.

MSc. Bernal Rivas Especialista en Archivística. Universidad de Costa Rica.

MSc. Ana María Botey. Historia de los movimientos sociales. Universidad de Costa Rica.abotey@gmail.com

\section{Miembros del Consejo Asesor Internacional:}

Dr. José Cal Montoya. Universidad de San Carlos de Guatemala.jecalm@correo.url.edu.gt

Dr. Juan Manuel Palacio. Universidad Nacional de San Martín.jpalacio@unsam.edu.ar

Dr. Eduardo Rey. Universidad de Santiago de Compostela.ereyt@usc.es

Dr. Heriberto Cairo Carou. Departamento de Ciencia

Política y de la Administración III - Universidad

Complutense de Madrid. hcairoca@cps.ucm.es

Dra. Rosa de la Fuente. Departamento de Ciencia Política y de la Administración III Universidad Complutense de Madrid rdelafuente@cps.ucm.es

Dr. Javier Franzé. Departamento de Ciencia Política y de la Administración III Universidad Complutense de Madrid. javier.franze@cps.ucm.es

Dr. Jaime Preciado Coronado Departamento de Estudios Ibéricos y Latinoamericanos. Universidad de Guadalajara japreco@hotmail.com

Dr. Gerónimo de Sierra. Vicerrector de la Universidade Federal da Integração Latino-Americana (UNILA) y Departamento de Sociología, Facultad de Ciencias Sociales de la Universidad de la República. geronimo@fcs.edu.uy

Dr. Antonio Palazuelos. Departamento de Ciencia Política y de la Administración III - Universidad Complutense de Madrid. palazuelosa@cps.ucm.es

Dr. Werner Mackenbach. Universidad Potsdam. werner.mackenbach@uni-potsdam.de
Dr. Guillermo Castro. Ciudad del Saber Panamá. gcastro@cdspanama.org

Dra. Natalia Milanesio. University of Houston.

nmilane2@Central.UH.EDU

Dr. Ricardo González Leandri. Consejo Superior de Investigaciones Científicas - España.

rgleandri@gmail.com

Dra. Mayra Espina. Centro de Estudios Psicológicos y Sociológicos, La Habana. mjdcips@ceniai.inf.cu

Dra. Montserrat Llonch. Departamento de Economía e Historia Económica Universidad Autónoma de Barcelona montserrat.llonch@uab.es

Dra. Estela Grassi. Universidad de Buenos Aires. estelagrassi@gmail.com

Portada:

Óleo de Juan Lepiani titulado Batalla de Arica (1880-Museo de los Combatientes de Arica) : Volumen 13- No. 1, artículo 2 "Sois vosotros valientes héroes. Somos nosotros simples humanos"... de David Angelo Coronado Canales. Fuente: http://members.tripod.com/ Guerra_del_Pacifico/ARICA3. html

"Diálogos Revista Electrónica de Historia" se publica desde octubre de 1999.

\section{Diálogos está en los siguientes repositorios:}

Dialnet

http://dialnet.unirioja.es/servlet/revista?tipo_busqueda=CODIGO\&clave_revista=3325

Latindex

http://www.latindex.unam.mx/larga.php?opcion=1\&folio=12995;

REDALYC

http://redalyc.uaemex.mx/src/inicio/FrmBusRevs2.jsp?iEdoRev=2\&cvepai=11

LANIC

http://lanic.utexas.edu/la/ca/cr/indexesp.html;

Repositorio de Revistas Universidad de Costa Rica http://www.latindex.ucr.ac.cr/

Directorio y recolector de recursos digitales del Ministerio de Cultura de España

http://roai.mcu.es/es/inicio/inicio.cmd

DOJAC Directory of open access \& Hybrid journals http://www.doaj.org/doaj?func=byTitle\&hybrid=1\&query=D

Biblioteca de Georgetown

http://library.georgetown.edu/newjour/d/msg02735.html

Asociación para el Fomento de los Estudios Históricos en Centroamérica

http://afehc.apinc.org/index.php?action=fi_aff\&id=1774 
Universidad de Saskatchewan, Canadá

https://library.usask.ca/ejournals/view/1000000000397982

\section{Monografias}

http://www.monografias.com/Links/Historia/more12.shtm

\section{Hispanianova}

http://hispanianova.rediris.es/general/enlaces/hn0708.htm

Universidad del Norte, Colombia

http://www.uninorte.edu.co/publicaciones/memorias/enlaces.html

Universidad Autónoma de Barcelona

http://seneca.uab.es/historia/hn0708.htm

Repositorio Invenia - Gestión del Conocimiento

http://www.invenia.es/oai:dialnet.unirioja.es:ART0000086144

Enlace Académico

http://www.enlaceacademico.org/biblioteca/revistas-en-formato-digital-centroamerica/

\section{Electronic Resources}

http://sunzi1.lib.hku.hk/ER/detail/hkul/3987318

Revistas académicas en texto completo

http://web.prw.net/ vtorres/

\section{Diálogos se anuncia en las siguientes} instituciones y sitios académicos:

\section{Maestroteca}

http://www.maestroteca.com/detail/553/dialogos-revista-electronica-de-historia.html

\section{Biblioteca de Georgetown}

http://library.georgetown.edu/newjour/d/msg02735.htm
Asociación para el Fomento de los Estudios Históricos en Centroamérica

http://afehc.apinc.org/index.php?action=fi_aff\&id=1774

Universidad de Saskatchewan, Canadá

https:/library.usask.ca/ejournals/view/1000000000397982

\section{Monografias}

http://www.monografias.com/Links/Historia/more12.shtml

Hispanianova

http://hispanianova.rediris.es/general/enlaces/hn0708.htm

Universidad del Norte, Colombia

http://www.uninorte.edu.co/publicaciones/memorias/enlaces.html

\section{Universidad Autónoma de Barcelona}

http://seneca.uab.es/historia/hn0708.htm

Repositorio Invenia - Gestión del Conocimiento http://www.invenia.es/oai:dialnet.unirioja.es:ART0000086144

\section{Enlace Académico}

http://www.enlaceacademico.org/biblioteca/revistas-en-formato-digital-centroamerica/

\section{Electronic Resources}

http://sunzi1.lib.hku.hk/ER/detail/hkul/3987318

Revistas académicas en texto completo http://web.prw.net/ vtorres/

La revista electrónica Diálogos es financiada por la Vicerrectoría de Investigación de la Universidad de Costa Rica
Citado en Dialnet - Latindex-

Redilac- Directorio y recolector de recursos digitales del

Ministerio de Cultura de España cc) creative 



\title{
HISTORIA, CIUDAD Y FILOSOFÍA LATINOAMERICANA EN JOSÉ LUIS ROMERO
}

\author{
Palabras claves \\ Historia, filosofía, urbanismo, cultura. \\ Keywords \\ History, philosophy, urbanism, culture
}

Fecha de recepción: 18 enero de 2012 - Fecha de aceptación: 8 febrero de 2012

\begin{abstract}
Resumen
Tras exponer la necesidad de pensar el espacio urbano en el que emergen y circulan los discursos de tal saber, se expone el lazo que describe Romero entre filosofía y ciudad. Tal relación parece débil en su análisis de la historia latinoamericana, en contraposición a su descripción de la filosofía europea. Aquello parece deberse a que Romero halla cierta renuencia en la filosofía latinoamericana a pensarse históricamente, en lo referente a la ciudad como su condición de posibilidad, lo que acercaría peligrosamente a cierto populismo, incapaz de pensar el carácter moderno de la cultura urbana latinoamericana.
\end{abstract}

\begin{abstract}
After exposing the necessity of thinking philosophical development in the context of the urban space where its discourses appear and circulate, we expose the link that Romero draws between philosophy and city. The relation is thought in a wekear sense in Latin America than in the European case. That might be considered because Romero finds a rejection in latin American philosophy to think itself historically, in that refers to the city as its condition of possibility, what puts it in close to a dangerous populism that cannot think the modern urban culture in Latin America.
\end{abstract}




\section{HISTORIA, CIUDAD Y FILOSOFÍA LATINOAMERICANA EN JOSÉ LUIS ROMERO1}

Alejandro Fielbaum S.

"Aquí no se ha engendrado ninguna idea que se parezca a mi Buenos Aires"

(Jorge Luis Borges)

Parece tan clara la primacía del tiempo sobre el espacio en la autocomprensión de la filosofía que ésta suele pensarse desde una historia sin geografía alguna. Claro está, aquello presupone y excede el concepto de tiempo que tal saber gesta, sobre una concepción que hacía derivar de éste un espacio así localizado secundariamente ${ }^{2}$. Al escribir sobre filosofía griega, romana, francesa o alemana, la narración de sus relevos no sería sino el de traslados que tornan prescindible el lugar en pos la universalidad ganada. Pues la filosofía de la historia -incluyendo, claro está, la filosofía de la historia de la filosofía - pareciera culminar la primacía analítica del tiempo sobre el espacio imperante en la historia de la filosofía. Al menos, claro está, desde la filosofía moderna -cuestión poco curiosa, dada la dificultad de pensar en la historia de la filosofía y en la filosofía de la historia antes de su moderno devenir. Aquello es claro en un autor situado en un momento de consolidación universitaria de la historia de la filosofía, y de su escisión de la historia de los acontecimientos. Desde esta última, Foustel de Coulanges remarcará la separación entre ambas erigiendo a la filosofía como una de las causas del fin de la ciudad ${ }^{3}$. Si bien la hipótesis del historiador francés puede sostenerse desde los pruritos cosmopolitas que rastrea en pensadores cínicos y estoicos, resulta difícil pensar que la crítica de Sócrates, Platón y Aristóteles se dirige efectivamente contra la ciudad griega. Aún cuando sus efectos pudiesen haberla desintegrado -lo cual parece más bien un argumento en la presentación de sí socrática como héroe que un argumento histórico-, éste jamás se erigió contra cierta idea de ciudad. Pues el pensamiento clásico no podía sino considerarse situado en una lengua y comunidad particular territorialmente delimitada y compartida. Al contrario, la promesa progresiva de lo moderno pareciera entonces ser la de superar infinitamente tal finitud. Bien lo supo Descartes al contraponer la imposibilidad de derribar las antiguas aldeas a la necesidad de fundar un nuevo comienzo intelectual, desde la metáfora del ingeniero que individualmente podría fundar una ciudad de mayor orden. En efecto, su metáfora para el pensamiento será el del gran camino que recorre la montaña ${ }^{4}$. Pero, claro está, para retornar con tal modelo al espacio heredado del que se aleja provisionalmente. Retirado de la ciudad, el pensador moderno inauguraría el nuevo tiempo contra el espacio existente y su problemática historia. Pues precisamente la historia de la ciudad sería lo inadministrable desde la razón cartesiana ${ }^{5}$. Huelga rememorar que la retórica autobiográfica 
allí es posibilitada precisamente en tal retiro -de la ciudad, y de su historia. Pues ésta le resultaría puramente exterior. El malestar de la filosofía en la inscripción pareciera modularse, por tanto, desde cierta incomodidad en una ciudad de la cual debe apartarse para recuperar interiormente la verdad que ésta olvida.

No resulta casual, en efecto, que los más prístinos ejemplos del rechazo filosófico a la ciudad provengan de aquellos autores que inauguran la tradición de la utopía o la autobiografía, en tanto modos de retiro de la ciudad existente. Podemos mencionar Platón o Campanella en el primer caso, a Agustín o Rousseau en el segundo. Pero recién en este último ya no se trata de imaginar una ciudad de distinta dimensión, sino de rehuir de ella. Pues Platón fue claro al señalar que sólo en el espacio urbano es posible la instrucción: "Los campos y los árboles nada me enseñan, y sólo en la ciudad puedo sacar partido del roce con los demás hombres". Al contrario, la admiración del ginebrino por Roma no resulta sino la de un espacio cuya virtud sería irrecuperable. Pues en la filosofía moderna, incluso la política pierde la necesaria vinculación a la ciudad. Es claro el contraste entre ello y el pensamiento político clásico. Para Strauss, en efecto, el tema de tal filosofía no sería sino la relación del hombre y la ciudad ${ }^{7}$. Así, Aristóteles buscaba conciliar la universalidad de la metafísica con la particularidad de la política por su necesario anclaje territorial a un espacio que no podía trascender el límite de la voz de quienes allí interactuaban ${ }^{8}$. Es claro que cualquier tentativa contemporánea de retomar un concepto delimitado de ciudadanía -contra la indeterminación territorial de las tentativas cosmopolitas- toma prestado el antiguo nombre de la ciudad mediante cierta operación metonímica. Éstas erigen el nombre de la comunidad y no el de la ciudad porque la primera se piensa contra la segunda ${ }^{9}$. Al contrario, en Aristóteles la preocupación por la ciudad es tan concreta que parte de su discusión política se sitúa en torno a la distribución de sus cuerpos y lugares:

"Los edificios consagrados a las ceremonias religiosas serán tan espléndidos como sea preciso y servirán, a la vez, para las comidas públicas de los principales magistrados y para la celebración de todos los ritos que la ley o el oráculo de la Pitonisa no han querido que fuesen secretos. Este lugar, que deberá poder verse desde todos los cuarteles que le rodean, será tal como lo exige la dignidad de los personajes que tiene que albergar. Al pie de la eminencia en que estará situado el edificio será conveniente que esté la plaza pública, construida como la que se llama en Tesalia Plaza de la Libertad. No se consentirá nunca que esta plaza se manche dejando tener en ella mercancías, y se prohibirá la entrada en ella a los artesanos, a los labradores y a todo individuo de esta clase, a menos que el magistrado expresamente los llame (IV, 11) ${ }^{10}$.

Es claro que el nombre de aquella plaza -como todo nombre, como toda plaza- no es casual. Pues precisamente la erección de tal lugar será lo que permita el desarrollo de la historia -harto distinto, a ésta como contemporáneo lugar de la memoria ${ }^{11}$. 
Tal preocupación por la ciudad como condición de posibilidad de lo público, en tanto espacio de recuerdo y de acción, es clara en la descripción de Arendt, cuyo diagnóstico sobre la irrupción social puede leerse como el olvido de aquella superficie $^{12}$. Quizás Maquiavelo pueda pensarse como el último autor con tal preocupación concreta por la ciudad, en tanto espacio limitado y colectivo de autodeterminación política ${ }^{13}$. Por ejemplo, en su conocido rechazo a que la guardia armada de tal libertad dependa de fuerzas externas a ella, o en su preocupación por el recuerdo que ésta pueda tener de su antigua vida libre -al punto que no podrá sino recomendar al Príncipe destruir tales recuerdos, o radicarse en ellos ${ }^{14}$. En tal sentido, es en la ciudad donde relampaguea la imagen del orden previo al presente. Tras ello, la ciudad parece haber escindido la dimensión mnémica de la política-oscilando su hegemonía entre uno y otro énfasis de acuerdo a la historia de las formas de pensarla. En la tradición contractualista la imposible rememoración del momento prepolítico resulta puramente individual, al igual que el cálculo que lleva a tal construcción desespacializada de lo público. Pues lo colectivo nace desde el pacto que suspende aquella dispersión, para constituir un orden cuyo centro ya no puede ser compartido. Lo allí constituido es el paso de la posibilidad de apropiarse del fruto del árbol al de tener la seguridad de la propiedad de su predio, extendiendo la imagen de Locke. El cuerpo político allí constituido difícilmente requiere de una ciudad. Antes bien, la comunidad que comienza a imaginarse es la de aquellos que jamás podrían reunirse en espacio común alguno ${ }^{15}$. Pues ciudadanos serían quienes compartan un pacto antes que una ciudad, y la inscripción corporal de tal inclusión se hará en nombre del suelo natural antes que de la urbe artificial -mientras que en Aristóteles eran ambas condiciones necesarias para ser miembro de lo público. Bien remarca Duso que el pensamiento moderno interpreta la polis como volk ${ }^{16}$. Aquello no podrá sino terminar estableciendo la ciudad como uno de los tantos temas de la administración pública antes que como condición de posibilidad de tal publicidad ${ }^{17}$. La culminación de tal proceso sería la pérdida de toda carga utópica asociada a su figura. Así, Buck-Morss diagnostica un contemporáneo divorcio entre el sueño y la ciudad ${ }^{18}$. Invirtiendo la dialéctica del tardío Medioevo, lo que haría libre no sería la ciudad sino el retirarse de ella. Pero antes que hacia un espacio preurbano, la liberación asociada a un consumo individuante pareciera jugarse en la habitación de fantasmagóricos espacios, en tanto espacios virtuales o turísticos. Tal retiro de la ciudad del espacio político -o, más precisamente, tal tentativa de desespacialización de la política- permite comprender que en el presente de tal proceso pueda señalarse, según la conocida tesis de Agamben, que la ciudad haya perdido el rol paradigmático en la reflexión política de Occidente para dejar tal lugar al campo de concentración ${ }^{19}$. Es decir, allí cuando la urbanización parece desplegarse incomparablemente en la historia, aquello que la habría fundado parece haberse retirado en el silencio que rodea todo destino. 
Tal tensión moderna entre ciudad y política podría ya pensarse desde la lectura hegeliana de Antígona, en tanto necesario avance hacia una universalización que suspende toda legitimación de la ley en el orden de la copresencialidad ${ }^{20}$. La modernidad logra desplegar el espacio productivo al margen de la política, mas no de la ciudad. Si antes la reproducción material de la vida se situaba en un espacio privado sustraído al de lo público, la posterior separación entre lugar de vivienda y de trabajo generará este espacio intermedio ${ }^{21}$. La posterior escisión moderna entre la familia y la ciudad remarcará aquello -desde la cual pensará Hegel la política como un espacio irreductible al orden de lo civil. Su dialéctica culmina simultáneamente la objeción a la ciudad existente tanto en la filosofía política como en la metafísica moderna, al remarcar su carácter exterior al infatigable despliegue del espíritu. Tal gesto parece necesario para conformar la bullada concepción de su filosofía como firma de su tiempo -y de su novedosa ubicación de toda filosofía en relación con éste. Pues aquello requiere la desconsideración de la ciudad. Ésta no sería sino lo dado. Es decir, aquello por trascender. Su espacio se situaría al comienzo del proceso de universalización cuya verdad supera toda lengua compartida, cuya legalidad trasciende todo territorio de aplicación. Ni siquiera objetualmente podría rescatarse. Aquello es claro en su consideración de la arquitectura, en tanto larvario momento de la historia del arte. Así, lo que definiría a la arquitectura sería su total exterioridad:

"Representa los inicios del arte, pues en sus inicios el arte todavía no ha hallado, para la representación de su contenido espiritual, los materiales ni las formas correspondientes, lo cual le obliga a limitarse a la simple búsqueda de la verdadera adecuación y a contentarse con un contenido y un modo de representación puramente exteriores. Los materiales con que trabaja este primer arte están desprovistos de espiritualidad; se trata de la pesada materia sometida a las leyes de la gravedad; en cuando a la forma, consiste en reunir de modo regular y simétrico las formaciones de la naturaleza exterior, en realizar la totalidad de una obra de arte haciendo de ella simple reflejo del espíritu"22.

Ajena al saber, pierde cualquier chance de alcanzar la propia interioridad. Lo que se lograría en la ciudad no sería, por tanto, más que superación. Así, también en el espacio moderno de la estética la ciudad resulta un nombre incómodo. Ninguna obra podría nacer de tan caótica yuxtaposición de formas. Lo rescatable en ella no será sino un fragmento aislado del contexto que la ha permitido, y de su herencia en la ciudad moderna. Aquello es claro en el rescate romántico del antiguo templo o monumento, como contraposición entre la placidez del antiguo lugar y la dispersión urbana. Tal testimonio del pasado no tendría continuidad alguna en el presente. O bien, en Heidegger, la tendrá contra la ciudad. Pues ésta rescatará raíces previas a la urbanización, desocultando un marco de singular mística y ausente historia:

"La obra templo, ahi alzada, abre un mundo y al mismo tiempo lo vuelve a situar sobre la tierra, que sólo a partir de ese momento aparece como suelo natal. Los hombres y los 
animales, las plantas y las cosas, nunca se dan ni se conocen como objetos inmutables para después proporcionarle un marco adecuado a ese templo que un buen día viene a sumarse a todo lo presente." 23 .

En efecto, Heidegger radicaliza el rechazo filosófico a la ciudad al vincular el trabajo filosófico al campesino. Pues la replicación nietzscheana del retiro heraclíteo al cerro en la marcha de Zaratustra ${ }^{24}$ pierde aquí cualquier posibilidad de retorno Siguiendo la notable frase de Taubes, interrumpe el camino de Jonia a Jena para dirigirse a los caminos del campo y sus perdidas sendas ${ }^{25}$. Así, la filosofía ya no se retiraría de la ciudad para observarla con mayor lucidez, sino que se resta definitivamente de ella -como el propio Heidegger, por cierto, realizó tras su repugnante inmersión en lo público:

"Mi trabajo se asemeja al del joven campesino cuando sube la pendiente remolcando el trineo de montaña y luego, una vez bien cargado con leños de aya, lo dirige a su cortijo en peligroso descenso; al del pastor cuando con su andar lentamente meditabundo arrea su ganado pendiente arriba; al del campesino cuando en su cuarto dispone en forma adecuada las innumerables tablillas para su techo"26.

Ahora bien, con todo lo -merecidamente- jocunda que pueda resultar cualquier recepción de tal postal, no deja de ser coherente con la estrategia heideggeriana de destrucción de la metafísica de la presencia. En particular, claro está, de la que ha imperado desde que el pensar pasaría a regirse desde el método como vía planificada y planificable ${ }^{27}$-acaso, desde que el sendero deja su espacio a la calle. La destrucción heideggeriana sólo podría trazarse, por tanto, mediante una meditación cuya inoperancia se escinda de toda arquitectónica. Pues tal diagrama no resultaría sino el de la aplicación categorial a aquello que resistiría toda formalización. Ferrater Mora recuerda, en efecto, el carácter clasificatorio de tal imagen en Kant y Pierce. Nada diría ésta de la realidad, pero nada de la realidad podría decirse sin ella $^{28}$. El despliegue de la filosofía requiere, por tanto, de cierto orden análogo al de la arquitectura. Bien recuerda Derrida la insistencia de tal metáfora en la filosofía, como signo de la capacidad de jerarquización de un orden filosófico cuya dirección se piensa al margen del orden allí trazado ${ }^{29}$. La filosofía requeriría entonces de la figura arquitectónica que rechaza, intentando regirlo desde tal pretensión de exterioridad para evitar que éste se vuelva contra sí hasta someterla a ser sólo un recorrido más en un orden descontrolado. No parece casual, entonces, que algunas de las más notables estrategias contemporáneas de repensar las posibilidades y tareas de la filosofía partan asumiendo su materialidad y experiencia como otra forma de ciudad. Pensamos, por ejemplo, en la consideración barthesiana de la ciudad como lenguaje que despliega el significante a quienes la recorren ${ }^{30}$, la analogía freudiana entre la ciudad y la estructura psíquica para graficar la imposibilidad de una representación mnémica total ${ }^{31} \mathrm{o}$ en la lúcida descripción wittgensteiniana de la infinitud 
e inanticipabilidad de la lengua al modo de la urbe: "Nuestro lenguaje puede verse como una vieja ciudad: una maraña de callejas y plazas, de viejas y nuevas casas, $y$ de casa con anexos de diversos períodos" 32 . Pero también en el abordaje directo de lo urbano distintos textos de intrínseco diálogo con la filosofía ${ }^{33}$, en tanto consideración de la urbe contemporánea como tema central de su reflexión. Lo cual, ciertamente, parece un mínimo de reconocimiento a donde se habita si se considera que la promesa de la filosofía no es tanto más - ni tanto menos- que la de la verdad de la experiencia.

Ahora bien, antes que profundizar en el carácter suplementario de la ciudad respecto a la metafísica, la ley o la obra de arte, nos interesa indagar en formas de pensar la historia de la filosofía que no caigan en tal punto ciego sobre tan necesaria relación. Pues tal actitud es vigente. Generalmente, mediante su silencio sobre la condición de posibilidad de la filosofía. Bien recuerda Jay, por ejemplo, la inexistencia de reflexión alguna sobre Frankfurt en la escuela de pensamiento allí nacida, pese a su constante observación a lo social y a portar tal nombre en su identidad como ningún otro grupo intelectual parece haberlo hecho. Pero cuando tal relación sí es pensada, como absoluta separación, tal gesto no parece cambiar. Por ejemplo, si recordamos la insistencia de Strauss en el rechazo a la ciudad como esencial característica de la filosofía ${ }^{34}$. Tampoco la inversión de tal binariedad parece una estrategia mucho más lúcida. Aquello puede achacarse a Lyotard, quien busca abolir la distancia de la filosofía con la ciudad. Si ésta ya no puede retomar la pregunta por el orden de la contemporánea megalópolis, al menos podría poseer la débil verdad de su desorden: "La filosofía no está en la ciudad, ella es la ciudad que piensa, y la ciudad es la agitación del pensamiento que busca su hábitat cuando lo ha perdido, cuando ha perdido la naturaleza" ${ }^{35}$. Ante la imposibilidad de regir la ciudad exógenamente, el saber filosófico se asume en la urbe para anular su singular materialidad desde otra estrategia. Es claro que ante aquella dificultad filosófica de pensar y pensarse en la ciudad, puede resultar lúcido recurrir a reflexiones provenientes de otros espacios intelectuales - precisamente, aquellos cuyo pensar consideren el espacio desde el cual provienen. Por ejemplo, Lefevbre es claro al remarcar que la relación entre la ciudad y la filosofía no es exterior. No sólo porque ésta sería posibilitada por la división social del trabajo y la respectiva emergencia de la ciencia y la filosofía, sino también porque partiría interrogándose desde y por la ciudad ${ }^{36}$. Impera destacar que su breve análisis no sitúa el espacio sobre el tiempo, sino que la ciudad es pensada también en su variación temporal. Allí puede hallarse cierta composición analítica en torno a historia, ciudad y filosofía. Desde el influjo de la historia de la cultura de inspiración decimonónica, ya en los señeros trabajos europeos de historia de las ideas pueden hallarse ecos de tal preocupación. Por ejemplo, en el trabajo de Jaeger sobre la cultura griega ${ }^{37}$, así como cierta inversión causal a lo que intentamos sostener en la singular hipótesis de Panofsky de la filosofía 
escolástica como causa de la arquitectura gótica ${ }^{38}$. Podemos también mencionar la existencia de notables trabajos posteriores sobre la Viena de comienzos de siglo como crisol del pensamiento de Wittgenstein ${ }^{39}$, el notable texto de Schorske sobre la preocupación por la ciudad en el pensamiento europeo ilustrado y post-ilustrado ${ }^{40}$ o la preocupación de Le Goff sobre el intelectual medieval en torno al renacimiento de las ciudades europeas ${ }^{41}$.

Los estudios sobre filosofía en Latinoamérica también pareciesen resistirse a cualquier narración de su historia en espacio concreto alguno -a diferencia de la importancia que tal cuestión ha ido ganando en los estudios sobre literatura ${ }^{42}$. Tal escisión entre ciudad y reflexión teórica resulta clara en dos notables estudios sobre la Argentina de comienzos del siglo XX. Mientras Sarlo soslaya rápidamente la preocupación por la filosofía al examinar la circulación de discursos desde la ciudad $^{43}$, Terán enfatiza en la producción teórica de la época sin preocupación por su dimensión urbana ${ }^{44}$. De manera más preocupante, en la clásica compilación sobre cultura urbana latinoamericana realizada por Morse el único texto sobre filosofía no hace mención alguna a la ciudad ${ }^{45}$. Mas pareciéramos poder hallar mayores indicios parciales en investigaciones que no refieren directamente al tema, tales como la preocupación de Guerra por la tertulia urbana como forma de sociabilidad moderna en la cual circulan ideas de avanzada ${ }^{46}$, la mención de Rama a los considerados "fundadores" de la filosofía latinoamericana como autores que remarcan el paso hacia la función ideologizante de la ciudad letrada ${ }^{47}$, el contraste realizado por Buarque entre la mayor producción intelectual en las colonias españolas que las portuguesas dada la renuencia de estas últimas la ciudad ${ }^{48}$ o la atención de Stoetzer a las capitales como espacio de mayor flujo de la Ilustración en Latinoamérica ${ }^{49}$ además de la curiosa hipótesis de Guarda, expuesta en dirección inversa, del pensamiento tomista como germen del orden urbano colonial ${ }^{50}$. Es claro que tal lista dista de ser exhaustiva, pero ya permite anticipar algunos de los temas que ocuparán durante décadas a quien más seria y largamente ha escrito al respecto. Nos referimos, claro está, al gran historiador argentino José Luis Romero.

No resultaría erróneo señalar que el interés de José Luis Romero por las ideas en Latinoamérica parte por casa. Su hermano Luis Alberto es uno de los nombres más importantes en la filosofía latinoamericana durante la primera mitad del siglo $\mathrm{XX}$-y no sólo por su producción intelectual, sino por su prominente figura dentro de la generación del campo discursivo que comenzó a apelar a tan curioso sintagma. Además de las constantes alusiones a la cercanía que obtuvo con Alejando Korn, se han remarcado las amistades de Romero con Rodolfo Mondolfo ${ }^{51}$ y Pedro Henríquez Ureña ${ }^{52}$. Sin embargo, resultaría un claro error considerar tal interés como accidental o externo a su labor de historiador ${ }^{53}$. Pues éste es comprendido por Romero como el del intérprete de cierta totalidad histórica, irreductible a una consideración estrecha o mecánica de lo factual. Los hechos le interesan dentro de estructuras cuya larga 
duración es enfatizada en la conformación de grupos y mentalidades que, trascendiendo tales acontecimientos, perduran como formas de vivir y comprender -por no decir, con mayor velocidad y menor reflexión, de culturas. La escasez de fuentes tradicionales u otros recursos de autorización comunes del historiador en sus textos desde allí se explica. Tales ausencias son compensadas con rica documentación textual apoyada en textos literarios y testimoniales cuyo valor histórico es, para Romero, tanto o más importante para la investigación historiográfica. Pues la objetividad en la que se despliega la vida sociocultural es comprendida como vivida por un ser biológico capaz de crear y actuar, situado tanto entre los objetos que ha creado como entre las ideas que despliega. Existe, así, un irreductible plano subjetivo como dimensión de la materialidad misma del vivir. Éste sería compuesta por una tríada de factores. En primer lugar, aquellas elaboraciones mentales, sistemáticamente vinculadas, que terminan dando lugar a instituciones. Éstas emergerían de objetivas situaciones, de las cuales surgirían como respuestas desde una reflexión que pareciera, con tal consideración, trascender cualquier explicación funcionalista del surgimiento de la institución. En segundo lugar, se sitúan las interpretaciones de la vida sociocultural. Las cuales también se yuxtaponen entre sí, en tanto relatos otorgados por la sociedad sobre su propia situación. La tercera dimensión sería la de los fines de la vida sociocultural ${ }^{54}$. Es claro que la elaboración filosófica se situaría en el segundo de aquellos planos, junto a ideas que podrían no considerarse como tal. Pero no sólo sería histórica al convivir con tales reflexiones de menor sistematicidad, sino también por su constitutiva tensión y relación con lenguajes políticos y administraciones institucionales, y su imposibilidad de reducirse a alguna de tales esferas. Y su ausencia de necesidad de la mediación de ninguna de ellas para tomar importancia en la historia.

Más aún, poseerían un carácter tan real como, potencialmente, disruptivo. Ya que Romero es particularmente consciente de la potencia del pensamiento ${ }^{55}$ para exceder aquello que la determina. Desde un esquema complementario, señala que la realidad histórica estaría compuesta tanto por el orden fáctico como por el potencial. En este último se sitúan representaciones y juicios, así como la tendencia a transformar lo fáctico desde la conciencia del sujeto histórico sobre su propia posición histórica. No es claro si todo el plano histórico subjetivo allí se anclaría, pero al menos así parece serlo respecto a las ideas. En tal sentido, lo que se piense de la historia pasa a ser un modo de transformarla. Ambos planos se combinarían sin linealidad ni igualdad, mediante relaciones contingentes sin jerarquías preestablecidas ${ }^{56}$. Así, podría considerarse que en determinado momento histórico las ideas han sido el principal factor de cambio, sin que aquello caiga en la mitología de explicar la historia desde sus cambios filosóficos. Las ideas podrían adquirir tal valor que el intérprete de la historia no podría prescindir de ellas para explicarse las acciones y pasiones allí desplegadas. Así, el trabajo histórico no sería sino el 
del estudio de la compleja y dialéctica relación entre lo acontecido y lo imaginado, analogado a la distinción spinoziana entre natura naturans y natura naturata ${ }^{57}$. Las ideas no sólo serían más que un reflejo de la realidad, al punto de ser constitutiva de ésta. Sino que, además, parecieran ser aquello que posibilita su transformación, en un trabajo en el cual imponer la legitimidad su espacio resulta parte fundamental de aquel proyecto. Pues las construcciones ideológicas de la sociedad se crean desde las estructuras, pero también contra las estructuras -incluso allí cuando éstas intentan defenderla ${ }^{58}$.

Tales reflexiones poseen mayor claridad en torno a lo que Romero termina por denominar como vida histórica. A fines de los años setenta, describe tan notable concepto, aún cuando señale seguir careciendo de una clara teoría de la estructura histórica. Describe la existencia de tres reinos conceptuales en el campo de la historia: Sujeto histórico, estructura histórica y proceso histórico. No parece casual que la segunda dimensión sea la más cercana a la de análoga posición en la tríada antes mencionada, recogiendo lo antes considerado como diversos planos de la misma dimensión. Mas tal reconceptualización gana cierta consideración del espacio institucional como parte misma de la dimensión intelectual. El primero de tales reinos remite a quien, individual o colectivamente, actúa en la historia. El segundo, a la vida histórica experimentada subjetivamente por tales sujetos, en tanto prolongación del pasado al presente. Es decir, se trata una actualidad cuya recepción del pasado requiere de la mediación selectiva que traza cierta disputa por tal herencia. Pues en esta dimensión no sólo se halla lo generalmente considerado como realidad -esto es, relaciones vigentes, objetos, funciones, y estilos de vida- sino también el conjunto de interpretaciones parciales o totales de la realidad supuesta. Además de las interpretaciones de tal realidad presente históricamente concebido, se sitúan también proyecciones del mismo. Si la dimensión institucional se añadía al plano de las ideas en este nuevo esquematismo como relaciones reales, la política se integra al situar aquí lo antes denominado como fines de la vida sociocultural. En tal sentido, el orden histórico en el que se ubican las ideas es pensado en un marco particularmente complejo. En aquel reino, la realidad es concebida como forma de vida, y su intelección como mentalidad ${ }^{59}$. Es claro que no podría pensarse la una sin la otra, pues la vida vivida no podría sino ser pensada. Pareciera necesario aquí recordar al temprano Heidegger sobre la dimensión constituyentemente interpretativa de la facticidad histórica ${ }^{60}$. Mas Romero suplementa cualquier posible apropiación individualizante de tal contexto al enmarcarlo dentro de su estructuración histórica. De allí la importancia del concepto de proceso histórico. Éste remite a la articulación de acciones y accidentes dentro de las cuales actúa el sujeto histórico, generando resultados que se instalan y renuevan la estructura previa. Dicho de otra forma, aquí se situaría aquello que le resulta exterior. Mas tal distinción parece puramente analítica. Pues la experiencia no es sólo la de responder 
ante tal situación histórica, sino también la de modular sus chances mediante un proceso creador y viviente - del cual emergerán distintos sujetos históricos. Huelga señalar que cada plano posee su propia dinámica dialéctica, desencadenando desde una compleja articulación la que sería la dialéctica fundamental de la vida histórica: La dialéctica entre la estructura real y la ideológica -parafraseada, también, como la dialéctica entre la realidad y su interpretación, o entre la realidad y el modelo de cambio para ella proyectada ${ }^{61}$. Debiese resultar claro que no se trata de un concepto despectivo de ideología. Al contrario, allí se halla una fuerte consideración de la capacidad intelectual de interpretar la realidad actual e imaginar la potencial.

Es clara la reminiscencia de tal consideración a la concepción hegeliana de la dialéctica entre espíritu objetivo y espíritu subjetivo como motor de la historia. Mas Romero se distancia de tal enfoque. Pues la dinámica histórica pareciera exceder cualquier posible finalización. Y su análisis, por tanto, requiere exceder el plano de la filosofía. Ciertamente, reconoce como sugerente y sólida a la filosofía de la historia de los siglos XVIII y XIX. Más aún, asume que la historia de la cultura recién habría sido posible desde las señeras reflexiones de filósofos como Herder, Montesquieu y Voltaire. No obstante, aprovecharía el impulso allí ejercido sin caer en sus alturas metafísicas. Pues la reflexión histórica otorga un análisis más concreto que el desplegado incluso por los autores con mayor preocupación empírica en la moderna filosofía de la historia, como Hegel o Vico ${ }^{62}$. Estos últimos también carecerían de rigor histórico, dado su afán generalizador. Así, sólo podría hablarse de historia de la cultura desde autores como Dilthey, Rickert, Huizinga o Cassirer ${ }^{63}$. Lo interesante en la consideración de Romero es su radical anclaje de la idea en la ciudad. No deja de ser meritorio aquello, pues entre los influyentes marcos conceptuales para pensar la relación entre historia e ideas tal consideración parece escasa. En tal sentido, destaca en Romero una consideración particularmente amplia de la dimensión histórica de lo cultural, al situarlo en el espacio concreto en que transcurre su vida histórica. Así, el estudio de las ideas debe tanto considerar tal totalidad como su particular campo, antes que considerar este último como lo que rige y explica las restantes dimensiones de la vida histórica, o bien al margen de ellas. En tal sentido, denomina ideas no sólo a las desplegadas más sistemáticamente, sino también a las menos rigurosas. Éstas poseen mayor importancia en la vida colectiva que las propiamente filosóficas. Lo que carecen en coherencia conceptual lo ganan en flexibilidad y anclaje vital. Entre ellas y las ideas filosóficas existiría cierto juego de irresoluble resultado ${ }^{64}$. Así, su análisis no idealiza ni a la filosofía ni al sentido común, sino que intenta poner atención simultáneamente a ambos discursos como distintos géneros dentro del mismo presente, evitando la fetichización del saber teórico o su reducción a asuntos prácticos. Aquello le permitirá ejemplificar tanto la acción económica y política como la reflexión metafísica como parte de fenómenos culturales $^{65}$. O incluir a la filosofía al trazar cierta cartografía histórica del género 
biográfico en Grecia y Roma. Así, la filosofía proveniente tras Aristóteles enfatizaría la reflexión en el hombre concreto ante la disgregación de la antigua coherencia otorgada por la previa comunidad espiritual ${ }^{66}$. También considerará la preocupación de Roger Bacon por la técnica como expresión del prometeico espíritu burgués de instrumentalización de la naturaleza, propia del ascenso de tal clase social ${ }^{67}$. E incluso su descripción de la crisis de sentido de la Europa contemporánea atenderá largamente a la filosofía como otro discurso, desde su especificidad, yuxtapuesto a otros géneros discursivos más imprecisos, pero que adquieren similar dirección: "Cada cual percibió el problema en el ámbito propio de su experiencia y reaccionó ajustando sus respuestas a sus propias preocupaciones" "68. Romero demuestra en tal reflexión un gran conocimiento de primera mano de los principales autores filosóficos de principios del XX, en torno a las corrientes vitalistas, fenomenológicas y existencialistas, en torno a la cuestión del hombre y su sentido ${ }^{69}$. Sin resumirse en la filosofía, la vida histórica allí experimentada bien se explica desde el recurso a los autores cuyo pensamiento es parte de la experiencia de tal época.

Ahora bien, tal preocupación por la filosofía no se replica en los análisis de Romero del desarrollo cultural latinoamericano. Aquello no puede explicarse por un posible desconocimiento de los incipientes desarrollos de las corrientes emergentes en Argentina. Tampoco por cierto descalce entre el modelo conceptual presentado y la particularidad latinoamericana. En efecto, su cuestionamiento a la escasez de tradición y la imprecisión de los contornos de la historia de las ideas se erige sobre ideas similares cuando ésta es aplicada a Argentina. Allí, lo buscado sería un cuadro conjunto de las ideas y opiniones en relación a los grupos sociales que las expresan, defienden o rechazan ${ }^{70}$. Tal cohabitación de conceptualizaciones de mayor y menor elaboración justificará la interesante estrategia de ordenar la exposición por épocas antes que por disciplinas, desplegando la distinción entre formas de saber como parte de cada una de las eras comentadas. En tal sentido, los textos filosóficos bien podrían pensarse como un dato valioso para comprenderlas. Pero en su descripción no aparecen como tal. Incluso en el momento en que pareciera resultarle más interesante: el movimiento estudiantil cordobés, y su necesaria revisión de valores de su época. Aunque los autores alabados por los estudiantes serían Bergson, Croce y los neokantianos, señala que en la literatura se plasma más fuertemente el significado de aquel proceso ${ }^{71}$. Casi al pasar, recuerda en tales sucesos el apoyo del ya mencionado Alejandro Korn. Y buena parte de su reflexión sobre el desarrollo de la filosofía en Argentina girará en torno a su figura. Al punto que pareciera no haberla antes de su trabajo. En efecto, el capítulo que abre el libro recién descrito no menciona desarrollo filosófico alguno, al referir a fines del siglo XIX. El segundo tramo epocal, referente al Centenario, le otorga al tema escuálidas cuatro páginas, las que destacan el crecimiento de la disciplina tras la primera visita de Ortega y Gasset. Mas en el tercero, situado en la época de mayor producción de Korn, 
son quince las páginas sobre filosofía. Valga mencionar que uno de los autores mencionados es Ricardo Rojas, a quien no podría inscribirse simplemente como integrante de la presunta filosofía argentina. Los otros son dos Korn e Ingenieros, ya presentados en el apartado anterior. La descripción de lo que advendrá tras ellos enfatiza en el incremento de figuras europeas, acompañadas de una mayor circulación de revistas especializadas y procesos de institucionalización universitaria de la filosofía. Su descripción culmina presentando el relevo antipositivista de Korn en los trabajos Romero y Astrada, además del creciente contacto con el pensamiento alemán, la creación de nuevas sociedades y editoriales y la lectura de textos de principios de siglo XX. Lúcidamente, Romero no margina de la discusión ni a los circuitos de producción ni a la recepción de la inteligencia europea. Sin ésta, resultaría difícil comprender el pensamiento argentino. Y también la realidad europea. Pues precisamente se trata de los autores mediante los cuales Romero intentaba comprender el mundo contemporáneo, sin replicar tal recurso a la filosofía para comprender su presente argentino. La recepción no parece igualmente productiva. Así, pareciera considerar antes a los filósofos europeos leídos en Argentina que a los productos de tal lectura en el país desde el que escribe.

Resulta notable, en el trabajo de Romero, el contraste entre el productivo anclaje historiográfico de la literatura y las ideas políticas en la Argentina de la cual surgen, y su dificultad de trazar el mismo gesto respecto a la filosofía. La única excepción se halla el trazo, ya expuesto, entre antipositivismo y movimiento estudiantil en Córdoba. Los restantes apartados sobre filosofía podrían haber sido insertados, aleatoriamente, en cualquier otra época cronológica en la medida en que se respetase la linealidad de una historia interna del pensamiento filosófico. Su progreso parece así desconectado de la historia de Argentina. Peor aún, de la historias de las ideas en Argentina. Se expone lo que la filosofía pueda señalar en cada época sin ensayar cierta hipótesis sobre su relación con ésta. Ya se ha señalado que Romero no sólo traza tal posibilidad metodológica, sino que además la desarrolla en torno a la realidad europea. En efecto, en el libro que comentamos lo logra cuando se presenta a Ortega y Gasset como intelectual de la España de su época ${ }^{72}$. Sintomáticamente, la filosofía argentina sólo poseería conexiones con la historia cuando el presente europeo se pasea por sus espacios. En tal sentido, pareciese existir cierto problema en la filosofía latinoamericana. Acaso, en su pretensión de ser tal. En efecto, lo que Romero rescata de Korn es que oriente su concepción de la historia en torno a los hechos antes que sobre su mera y erudita enunciación $^{73}$. El intento de gestar filosofía en Latinoamérica pareciera entonces caer en el último pecado, aislándose de su presente histórico. Irónicamente, el recurso a un autor de la filosofía latinoamericana es el que permitirá a Romero desconsiderarla como campo discursivo. Lo cual, por cierto, no se justifica gremialmente al cuestionar que no repitan su perspectiva. Romero reconoce que el filósofo no se dedica 
sistemáticamente a la investigación histórica. Pero, dada su curiosidad espiritual, no podría dejar de inquietarse por ella ni prescindir de su saber ${ }^{74}$. Pero ésto es lo que pareciese faltar en la incipiente filosofía latinoamericana, cuyo intento de localización remitiría a un espacio cuyo tiempo no sería sino el europeo.

En tal sentido, el problema de la filosofía en Latinoamérica pareciera ser la inexistencia de un sujeto histórico que pudiese allí expresarse. Dicho más brutalmente, ésta pareciera no acontecerle a nadie más que a quienes la escriben. Es claro que aquello podría decirse, en sentido estrecho, de todo texto. Mas el interés histórico en tal tipo de producción posee reside en su capacidad de elaborar cierta mediación entre interpretación y realidad, necesaria en la articulación de sujetos históricos. De ahí el cuestionamiento de Romero a cualquier consideración marxista del saber en términos de éste como superestructura ${ }^{75}$, así como a la pretensión de un saber puro o descontextualizado:

"La economía, la moral y la política son cosas que le ocurren a alguien, que es el sujeto de todos los procesos al mismo tiempo: es a la sociedad argentina, a la sociedad nacional, a quien le ocurren todas esas crisis, y es ella la que debe ser examinada con obsesiva precisión"76.

El problema de la filosofía es que habría logrado, efectivamente, mantenerse en el margen de una ciudad de la que reniega. Aquello no acontece en el desarrollo histórico de las ideas políticas en Latinoamérica, las cuales aparecen en los distintos modelos de ciudad descritos por Romero. Y todo el despliegue de éstas se situaría en torno a la cuestión del progreso cultural y político, al punto que el problema del liberalismo sería el nudo más importante en la historia y cultura latinoamericana ${ }^{77}$. Tales discusiones se remontan al siglo XVIII y su preparación de la Independencia en torno a la lectura de los autores ilustrados en la ciudad. Éstas habrían sido centros de recepción y emergencia de actividad cultural e intelectual ya desde las ciudades de Indias. Pese a su función primeramente administrativas, logra allí destacar a teólogos y universitarios -además, claro está, de inquisidores y moralistas ${ }^{78}$. La posterior ciudad criolla poseería una marca ilustrada más clara, al punto que habría nacido desde las renovadoras ideas ilustradas que acentuaron su ideología. Sus tertulias excederían temáticas literarias, para otorgar paso a discusiones políticas, filosóficas, económicas y científicas ${ }^{79}$. De gran riqueza y dinamismo cultural, la posterior ciudad burguesa se mantendrá como el espacio de discusión política en Latinoamérica, recibiendo a Marx y Bakunin en emergentes grupos obreros y a la filosofía del progreso en la burguesía ${ }^{80}$. Es decir, incluso albergará la posibilidad de más de una corriente de discusión en sus calles.

Es claro que en las ciudades anteriores también existía discusión en la ciudad sobre ideas políticas, pero no se trataba de la discusión entre dos ideologías urbanas. De la misma forma que en la posterior ciudad masificada se perderá tal práctica 
puramente citadina, aún cuando se trate de la ciudad que más podría preciarse de serlo desde indicadores cuantitativos. Ya que la ciudad, según indica lúcidamente Gorelik, es vista por Romero en torno a la existencia de lo público ${ }^{81}$. Lo cual habríase perdido, precisamente cuando sus necesidades y políticas se orientan a solucionar problemas de vivienda de un convivir del que ninguna propuesta de orden podría emerger. Pues allí pasa a regirse desde la ausencia de reflexividad o proyecto que trasciende lo inmediato. Pues la ciudad, para Romero, es primeramente una actitud. Antes que por niveles de conexión, pavimentación o agrupación, se juega en ser una forma de habitar -de la cual podrá nacer, eventualmente, la filosofía. La ciudad introduce, con ímpetu, lo nuevom Permite cierta modernidad en Latinoamérica. Pues aunque no posea su correlato económico, desde la dimensión cultural las ciudades latinoamericanas alcanzan cierta mentalidad moderna. Es decir, cierta toma de posición racional y colectiva ante lo público capaz de dirigir una determinada renovación del orden social. De hecho, allí donde faltó su burguesía ilustrada, las clases rurales habrían permanecido pasivas ${ }^{82}$. Es claro que tal vinculación de la ciudad a la novedad y el campo al tradicionalismo posee larga data en el continente. Incluso podría rastrearse antes de su popularización en la escritura de Sarmiento. Según Annino, ya en el iusnaturalismo católico colonial puede hallarse tal contraposición ${ }^{83}$. Tal realidad no podría pensarse como la coexistencia de dos mundos independientes en todo sentido. Bien cuestionan Faletto y Kirkwood, en efecto, la existencia de una total demarcación entre campo y ciudad como eje del conflicto decimonónico, pues ambos espacios se suplementan económicamente ${ }^{84}$. Sin desconocer aquello, Romero considera que tal separación genera formas históricas de vida distintas. Aquello le permitirá hallar más similitudes entre Bogotá y Buenos Aires, que entre Lima y la sierra peruana. Pues no sólo se trataría de realidades distintas, sino también de formas diferentes de interpretar la realidad de ambos estilos de vida, y la relación entre éstos y su interpretación de sí. Lo que caracterizaría a la ciudad sería el pensarse a sí misma como proyecto. Es decir, aún cuando podría no haber existido jamás ciudad en Latinoamérica, si habría acontecido el hábito urbano de pensar la vida colectiva como citadina.

Ahora bien, con ello Romero no cae en la fácil binariedad entre un campo simple y una ciudad compleja. De hecho, recalca que también en el campo existe más de una forma de autocomprensión. El que la ciudad y el campo sean una forma de vida no significa que éstas posean una imagen concluyente de sí. Sino una forma de interrogarse por su existencia, cuyas respuestas variarán a lo largo de la historia, y también en cada uno de sus presentes dada la existencia de más de un sujeto histórico en cada uno de ellos. Así, a fines de colonia puede hallarse en el campo tanto la ideología rural señorial como la de quienes huyen de la ciudad y construyen un antiurbanismo de cuño popular ${ }^{85}$. Posteriormente, tanto la gauchesca como el romanticismo idealizarán el campo como contraposición a la modernización de 
las ciudades. El campo añorado no correspondería al pasado real de una vida sin conflicto alguno, sino a una construcción intelectualmente mediada. No deja de ser notable que similares reflexiones sean desarrolladas Ángel Rama ${ }^{86}$ y Raymond Williams ${ }^{87}$ para discutir las visiones melancólicas de la vida rural. Tal amalgama de la versión hacendal y la popular genera un criollismo sentimentalista opuesto al cosmopolitismo urbano. Aquello acontecería durante la escisión de la derecha latinoamericana entre la oligarquía liberal urbana y los grupos señoriales ligados al campo. Estos últimos forjarían tal imagen, mientras intentan modernizar productivamente la economía agraria ${ }^{88}$. En tal sentido, el espacio rural estaría tan sometido a los vaivenes históricos como el urbano,. Sólo podría pensarse como estático cuando se enfatiza su dinámica económica. Lo que diferenciaría a la forma de vida histórica urbana de la rural no es que sólo la ciudad se piense o que el campo no cambie, sino que el campo se piensa a sí desde la continuidad y la ciudad desde el cambio. Y que, dada la ausencia de un espacio textual extendido en el campo, generalmente ambas operaciones se desarrollen en la ciudad. Así, ésta logra inventar, simultáneamente, la tradición rural y la novedad urbana. Parte de la ideología rural será aquella ausencia de reflexividad sobre el condicionamiento histórico de su presente y de los discursos que buscan representarlo -desde lo cual podría explicarse la insistencia intelectual en Latinoamérica, tantas veces reiterada, de la oralidad como fuente de todo saber rural (e incluso, nacional o continental). Tal distancia entre ideologías no remitiría a cierto momento histórico, sino a una infinita tensión entre dos tipologías que permitiría explicar los procesos ideológicos latinoamericanos desde su constitutiva coexistencia entre tradición y modernización:

"Quizás puedan explicarse los procesos de la sociedad latinoamericana de diversas maneras.
Pero si se atiende a la significación de las ideas, especialmente cuando se convierten en
ideologías, esta dialéctica entre una ideología urbana y otra rural expresa con bastante
fidelidad ciertas tendencias sostenidas en la vida social y cultural: es como un espejo donde
se reflejan las tensiones entre campo y dos áreas donde el asentamiento humano ha sido muy
diferente en Latinoamérica y donde han surgido dos formas de vida y de mentalidad que
pueden extrapolarse en dos ideologías en perpetuo conflicto" ${ }^{89}$.

En efecto, incluso en las pequeñas ciudades habría existido cierta conmoción social tras el impacto de las ideas ilustradas ${ }^{90}$. Es claro, entonces, que su posibilidad no se explica por una cuestión demográfica. La circulación de ideas de cierto grado de sistematicidad -aún cuando no todas puedan preciarse de ser filosóficas- resultaría entonces sólo posible en un espacio que asume la posibilidad del diálogo y celebra la necesidad del cambio, como lo es la ciudad. No resulta difícil a las ideas políticas progresistas - del liberalismo en adelante- asumir aquello. Pues precisamente en la ciudad verían la chance de su realización. Incluyendo, como parte de ésta, el poder circular en ella. Mas aquello no pareciera replicarse cuando el pensamiento latinoamericano busca constituirse como filosófico. Romero menciona los 
nombres propios más influyentes en la primera mitad del siglo XX mexicano Vasconcelos, Gaos, Ramos y Zea- como ejemplos de la combinación de lo indígena y lo vernáculo propia de la ideología rural ${ }^{91}$. La obsesión de tales autores por el origen les impediría asumir que la ciudad ya no es el espacio de la Latinoamérica cósmica, el paso lento o la inseguridad mestiza. Sería tal su resistencia a asumir la ciudad que Vasconcelos será también incluido dentro de los autores antiliberales que fundamentan la posibilidad de un pensamiento político populista ${ }^{92}$. Impera señalar que Romero señala que esta última forma de hacer política, por antiintelectualista que sea su presentación, posee sus ideas -en efecto, Romero recuerda la influencia allí ejercida por Sorel, Pareto, Maurras y Daudet ${ }^{93}$. Y, como forma política de una sociedad de masas, se ejerce contra la ciudad y su filosofía. Ciertamente, aquello no desconoce la recurrente descripción del populismo como movimiento que favorece la economía urbana sobre la agraria. Pero su rescate de la ciudad se da contra cualquier posibilidad de integración en ella mediante el espacio público, amparándose antes en prestaciones que se legitiman contra la discusión en tales foros. Y aquello no dejaría de ampararse en la ceguera histórica de intelectuales urbanos que renegarían de la ciudad que posibilita su reflexión. Su apelación a lo popular como mantención o recreación de prácticas de resistencia a la ciudad impediría la continuidad con el proceso cultural de urbanización latinoamericana. En tal sentido, la vorágine populista atenta directamente contra la agenda intelectual de autores como Romero. Pues destruye la posibilidad de un orden urbano, político y categorial fundado en cierta racionalidad de la cual la cultura urbana podía, sin dejo de modestia, preciarse.

Ahora bien, la conclusión de tal cuestionamiento no es la imposibilidad de cierto pensamiento latinoamericano. Ni que éste deba reducirse a acompañar o dirigir transformaciones políticas. Romero defiende, en primer lugar, la existencia irreductible de cierto espacio académico con palabras cuya estratégica vigencia parece indiscutible:

"La Universidad, ciudadanos, no ha ofrecido mejoras de salarios, es innegables, porque no es misión suya otorgarlas. Pero la Universidad ha trabajado en la elaboración de las ideas que han permitido un día hablar de las reivindicaciones económicas y sociales sin que nadie se atreva ya a negar su justicia"94.

Y no claudica en llamar, lo allí pensado, como pensamiento argentino. Polémicamente, asegura la existencia de tal pensamiento, tal como ha existido un pensamiento francés o alemán. Sostiene aquello cuestionando la idea de que el contenido de tal pensamiento sea puramente receptivo. Antes que argumentar a favor de cierta originalidad, astutamente esboza el argumento inverso al recordar la influencia inglesa en el pensamiento francés del siglo XVIII. Es decir, uno de los ejemplos más claros de lo que podría ser un pensamiento local -tanto por la 
cantidad y calidad de sus pensadores, como por el anclaje nacional de buena parte de las problemáticas que despliegan- sólo puede comprenderse más allá de sus fronteras. En tal sentido, el pensamiento argentino no sería puramente autóctono porque ninguno podría serlo. Si un pensamiento nacional fuese aquel que sólo se nutre de lo pensado, tal sintagma sería imposible ${ }^{95}$. Ahora bien, esto no significa que exista una continuidad total con lo recibido como crisol de tal pensamiento. Discute aquello al oponerse al hispanismo tradicionalista que cuestiona la existencia de un pensamiento argentino, en nombre de la idiosincrasia compartida con España. Pues la chance del pensamiento no se jugaría en su fuente doctrinaria. Sino en cierto espacio creativo de lectura. Éste debe ser la ciudad, pero no cualquiera. De ahí la importancia de la actitud que ésta tome ante lo que importa. Requiere de la emergencia de cierta recepción productiva del pensamiento local, entendido como todo lo pensado desde y sobre el país -incluyendo, incluso, lo no escrito. Así, el pensamiento argentino no sería tanto una historia intelectual como una experiencia interpretativa. Antes que por la originalidad, la pregunta sobre la existencia de tal pensamiento se dirime en torno a lo vivido y repensado de forma militante, hasta proyectarse e incluirse en la realidad. No se cifraría entonces en cierta escuela o historia, sino en un estilo ${ }^{96}$. En torno a éste, y no a cierta disciplina o institución, habría que considerar el pensamiento argentino, irreductible a la discusión política local o a la lectura filosófica internacional. Romero no claudica en tacharlo de grande y profundo ${ }^{97}$. Menciona allí las críticas al positivismo de autores como Astrada, Korn, Romero y Rivarola, además de la explícita influencia de Scheller, Husserl, Heidegger, Bergson, Croce y Ortega y Gasset. En tal pensamiento habría que incluir toda chance de filosofía en Latinoamérica, desde la imposibilidad de su pureza. Pues antes que sincrético, el pensamiento especulativo argentino se caracteriza por su condición ecléctica -en contraposición al pensamiento político, cuya composición más unificada es posible por la simultaneidad de su interpretación teórica y práctica de la realidad nacional ${ }^{98}$. En tal sentido, resulta plausible cierta filosofía argentina, y con toda la fuerza que puedan tener ambos conceptos. Es decir, una reflexión fundamental situada en un espacio particular. Pero aquello sería posible en la medida que tal reflexión se inserte desde un zigzagueo conceptual que no referirá directamente al espacio de su presente, pero que se deja pensar desde allí. Y al cual puede oponerse, pero en nombre de lo allí prometido. Dicho de otra forma, la filosofía podría cuestionar la ciudad existente, pero no en nombre de ruralidad alguna. En tal sentido, las posibilidades de composición de tal eclecticismo son claras. Sus límites no son sino los de la urbe.

Ahora bien, impera preguntarse por qué tal límite entre el campo y la ciudad se dibuja también entre un país y otro en lo referente al pensamiento. Para bien o para mal, el análisis histórico de Romero busca pensar los procesos latinoamericanos desde cierta narración común -ciertamente, desde el modelo argentino. De allí la 
extrañeza de que no se refiera a un pensamiento filosófico latinoamericano, siendo tal territorialización sólo utilizada para el pensamiento político.

Ciertamente, podría pensarse aquello desde cierta forma tajante de pensar la tajante separación entre una y otra cultura en la conceptualización de Romero sobre la morfología cultural y sus procesos de intercambio, transmisión e imposición ${ }^{99}$. Pues aquello impide pensar la simultaneidad de la recepción y la resistencia. Aquella será una elaboración posterior en la crítica cultural latinoamericana, en torno a las figuras de la transculturación, la hibridez o la heterogeneidad -sin desconsiderar las importantes, e irreductibles, distancias entre todas ellas. Sin embargo, las descripciones otorgadas por Romero en torno a los procesos latinoamericanos o bien permiten pensar la existencia de tales contactos entre países, o bien da a entender a Latinoamérica como una forma cultural de características compartidas.

Descartando aquello, bien podría construirse cierta hipótesis en torno al ya mencionado rechazo de ciertos autores mexicanos y el rescate de algunos argentinos. Mientras los primeros intentan realizar cierta filosofía de dimensión latinoamericana desde temáticas propias, los segundos enfatizarán en el carácter argentino de su circuito y universal de sus temáticas. Y es probable que desde Romero sea pensable, desde última estrategia, algo así como una filosofía que pueda preciarse de ser latinoamericana. Es decir, un pensar que no renuncie ni a la filosofía ni a su propio espacio, capaz de pensar lo segundo desde lo primero y de situar lo primero en la experiencia de lo segundo. En tal sentido, antes que cierta imposibilidad, Romero constataría cierta ausencia histórica. La filosofía latinoamericana se ofrece como chance. Si el orden de lo potencial asociado a las ideas carga consigo la promesa de la transformación, aquello bien podría pensarse desde tal situación de la filosofía. Es claro que no evaluó tal proceso, cuyos primeros pasos fueron contemporáneos a su notable trabajo. Pero éste no sólo permite anclar la filosofía en su historia desde la necesaria mediación de su espacio urbano, sino también pensar la posibilidad de ampliar su espacio de circulación hacia otras ciudades, en tanto reflexión que trascienda al caso argentino -análogamente, por cierto, al esfuerzo por él realizado en torno a la historia. Y si ésta se juega en su experiencia antes que en origen u ontología alguna, la pregunta por la posibilidad de la filosofía latinoamericana ya no se jugaría en la comunidad de cierto origen étnico o cultural o en cierta realidad común frente a la cual se sitúa. Sino, de forma simultáneamente más local y moderna, en pensar si puede compartirse en sus distintas ciudades la intelección particular de cierta experiencia histórica que las una y trascienda.

\section{CITAS Y NOTAS}

$1 \quad$ Parte de este artículo fue presentado en el Simposio "La filosofía latinoamericana y su historia: Balances, Debates y Proyecciones" realizado en la Universidad de Santiago en Noviembre del 2010. 
2 Massey, Doreen, "La filosofía y la política de la espacialidad”, en Arfuch, Leonel (Comp.) Pensar este tiempo: espacios, afectos, pertenencias. Paidós, Buenos Aires, 2005.

3 Fustel de Coulanges, Numa Denis, La ciudad antigua. Madrid, EDAF, 1992, p 331-339.

4 Descartes, René, Discurso del método. Losada, Buenos Aires, 1959, pp.40-42.

5 Rojas, Sergio, "Desde la calle no se ve la ciudad", en VVAA, Calle y acontecimiento. FONDART, Santiago, 2001, p.7

6 Fedro.

7 Strauss Leo, El hombre y la ciudad. Amorrortu, Buenos Aires, 2006, p. 9.

$8 \quad$ Política IV, 4.

9 Pensamos, claro está, en autores como Walzer o Taylor. Y, desde Richard Sennett, tales proyectos de comunidad entre iguales -aún cuando se legitime en nombre de la diferenciacomo una reaccionaria barricada a la ciudad.

El declive del hombre público. Península, Barcelona, 2002.

10 Aristóteles, Política IV, 11.

11 Es claro que pensamos aquí en el trabajo de Pierre Nora -aún cuando muchas de sus distinciones entre historia y memoria nos resulten, por decir lo menos, discutibles. Al respecto, Nora, Pierre, "La aventura de Les lieux de mémoire", en Cuesta, Josefina (Editora), Memoria e historia. Marcial Pons, Madrid, 1998.

12 En particular, véase, Arendt, Hanna, Sobre la revolución. Alianza, Madrid, 2004.

13 No será casual entonces que una de las historias intelectuales que, sin inscribirse en la historia de la ciudad, más podría colaborar a repensar tal relación se oriente a Maquiavelo - desde un énfasis lectivo en su orientación a la ciudad y su presente.

Pocock, John, El momento Maquiavélico: el pensamiento político florentino y la tradición republicana atlántica. Tecnos, Madrid, 2000.

14 Maquiavelo, Nicolás, El Príncipe: $V$.

15 Predeciblemente, tomamos tal término y su interpretación de Benedict Anderson (Comunidades imaginadas. Fondo de Cultura Económica, México D.F., 2007.

16 Duso, Guiseppe, "La crítica hegeliana del iusnaturalismo en el periodo de Jena”, en Duso, Guiseppe (Editor), El contrato social en la filosofía política moderna. Alfonso el Magnánim, Valencia, 1980, p.341.

17 En tal sentido, lo descrito por Habermas sobre la conformación de cierto espacio público burgués no contradice lo aquí expuesto, al ser un espacio carente de posibilidad de decisión. La vocación universalista de su inclusión y circulación, en efecto, testimonia indiscutiblemente tal pérdida de la ciudad como espacio de referencia de lo político.

Habermas, Jurgen, Historia y crítica de la opinión pública. G G Mass Media, Barcelona, 1991.

18 Buck-Morss, Susan, "La ciudad como ensueño y mundo de catástrofe", en Walter Benjamin, escritor revolucionario. Interzona, Buenos Aires, 2005, p.251 
20 Dusso, La crítica hegeliana.

21 Es claro que, en tal descripción, seguimos lo señalado por Hanna Arendt en La condición humana (Paidós, Buenos Aires, 2005) así como las descripciones de Weber sobre la constitución del espacio productivo moderno en Economía y Sociedad: esbozo de una sociología comprensiva (Fondo de Cultura Económica, México D.F., 1964).

22 Hegel, Georg Willhelm Friedrich, Arquitectura. Kairós, Barcelona, 1981, p.21.

23 Heidegger, Martin, "El origen de la obra de arte”, en Sendas Perdidas, (Losada), Buenos Aires, 1960, p.33

24 Nietzsche, Friedrich, Así habló Zaratustra. Alianza, Madrid, 1997.

25 Taubes, Jacob, “Notas sobre el surrealismo”, en Del culto a la cultura. Elementos para una crítica de la razón histórica. Katz, Buenos Aires, 2007, p.166.

26 Heidegger, Martin, “¿Por qué hermanemos en la provincia?”. Eco, n5, Tomo VI, 1963.

27 Heidegger, Martin "La falta de nombres sagrados”. Acento n², pp. 29-32.

28 Ferrater Mora, José, “Filosofía y Arquitectura”, en Cuestiones disputadas. Ensayos de filosofía. Revista de Occidente, Madrid, 1955, p. 59.

29 Derrida, Jacques, "La metáfora arquitectónica", en No escribo sin luz artificial. Cuatro Ediciones, Valladolid, 1999.

30 Barthes, Roland, "Semiología y Urbanismo", en La aventura semiológica. Paidós, Barcelona, 1990, p. 266.

31 Freud, Sigmund, "El malestar en la cultura", en Obras Completas. Tomo III. Biblioteca Nueva, Madrid, 1973, p. 3021.

32 Wittgenstein, Ludwig, Investigaciones filosóficas: 18

33 A modo de ejemplo, pensamos en textos ciertamente irreductibles a ejemplaridad alguna, tales como Benjamin, Walter, Diario de Moscú. Taurus, Madrid, 1990; Dirección Única. Alfaguara, Madrid, 2005; El libro de los pasajes. Akal, Madrid, 2005; Infancia en Berlín hacia 1900,. Alfaguara, Madrid, 1982; Simmel, Georg, "La metrópolis y la vida mental". Bifurcaciones $n^{\circ} 4$; Foucault, Michel, Vigilar y castigar. Siglo veintiuno, Buenos Aires, 2002; "Teoría de la deriva", en Internacional Situacionista, Textos completos en castellano de la revista. Volumen I: La realización del arte. Literatura Gris, Madrid, 1999; Jameson, Frederic. El posmodernismo, o, la lógica cultural del capitalismo avanzado. Paidós, Barcelona, 1991 Marchant, Patricio, "La guardia de la ciudad", en Escritura y temblor. Santiago, Cuarto Propio, 2000; Nancy, Jean-Luc, La creación del mundo o la mundialización. Paidós, Barcelona, 2003.

34 Strauss, Leo, "Introduction", en Persecution and the art of writing. Free Press, Illinois, 1952, p.24.

35 Lyotard, Jean-Francois, “Zona”, en Moralidades posmodernas. Tecnos, Madrid, 1998, p.22. 
36 Lefevbre, Henri, "La filosofía y la ciudad", en El derecho a la ciudad. Península, Barcelona, 1973.

37 Jaeger, Werner, Paideia: los ideas de la cultura griega. Fondo de Cultura Económica, México D.F., 1942-1945.

38 Panofsky, Erwin, Arquitectura gótica y escolástica. Buenos Aires, Infinito, 1951.

39 Janik, Allan ; Toulmin, Saul; La Viena de Wittgenstein. Taurus, Madrid, 1974.

40 Schorske, Carl, "The Idea of the City in European Thought: Voltaire to Spengler", en Burchard, Johnn; Handlin, Oscar (Editores), The historian and the city. The MIT and Harvard University Press, Massachussetts, 1963.

4140 Jacques, Los Intelectuales en la Edad Media. Gedisa, Barcelona, 1996, p.25.

42 Por ejemplo, Ramos, Julio, Desencuentros de la modernidad en América Latina : literatura y política en el siglo XIX. Cuarto Propio, Santiago, 2003.

43 Terán, Oscar, Vida intelectual en el Buenos Aires fin-de-siglo (1880-1910) : derivas de la "cultura científica”. Fondo de Cultura Económica, México D.F., 2000.

44 Sarlo, Beatriz, Una modernidad periférica : : Buenos Aires 1920 y 1930. Nueva Visión, Buenos Aires, 1988.

45 Krauze, Enrique, "José Vasconcelos en 1921: arquitecto del espíritu”, en Hardoy, Jorg ; Morse, Richard (Editores), Cultura urbana latinoamericana. CLACSO, Buenos Aires, 1985.

46 Guerra, Francois-Xavier, "Una modernidad alternativa”, en Modernidad e independencias. Ensayos sobre las revoluciones hispánicas. Fondo de Cultura Económica Madrid, 1992.

Rama, Ángel, La ciudad letrada. Norte, Hanover, 2002, p. 111.

Buarque de Holanda, Sergio, Raízes do Brasil. Companhia das Letras, Sao Paulo, 1995, pp.119-121.

49 Stoetzer, Carlos, El pensamiento político en la América española durante el periodo de la emancipación (1789-1925). Volumen I. Instituto de Estudios Políticos, Madrid, 1966, p. 53.

50 Guarda, Gabriel, "Santo Tomás y las fuentes del indianismo urbano". Boletín de la Academia Chilena de Historia $n^{\circ} 72$ año XXXII, 1965 (Primer Semestre), pp. 5-50.

51 Bagú, Sergio, “José Luis Romero: Evocación y evaluación”, en VVAA, De historia e historiadores. Homenaje a José Luis Romero. Siglo Veintiuno, México D.F., 1982, p.27.

52 Halperín., Tulio, “José Luis Romero y su lugar en la historiografía argentina”, en Romero, José Luis, Las ideologías de la cultura nacional y otros ensayos. Centro Editor de América Latina, Buenos Aires, 1982, p. 188.

53 Huelga indicar que el seguimiento que realizaremos de temáticas varias en el trabajo de Romero se circunscriben, fundamentalmente, a sus escritos sobre Latinoamérica. Las menciones a otras de sus obsesiones sólo serán utilizadas en función de lo primero. 
54 Romero, José Luis, "Historia y ciencias del hombre: la peculiaridad del objeto”, en La vida histórica. Sudamericana, Buenos Aires, 1988.

55 Claramente, tomamos tal frase de Agamben. Y acaso no resultaría erróneo arriesgarse a cierta lectura de corte más filosófico -implícita, ciertamente, en todo análisis histórico- de Romero desde allí, en tanto pensador de la imposibilidad de la actualidad sin las potencias cuya chance el pensar abre una y otra vez.

56 Romero, José Luis, “Reflexiones sobre la historia de la cultura”, en La vida, p.124.

57 Romero, José Luis, Estudio de la mentalidad burguesa. Alianza, Madrid, 1987, p. 24.

58 Romero, José Luis, Estudio de la mentalidad, p. 28.

59 Romero, José Luis, "El concepto de vida histórica”, en La vida, p. 18.

60 En particular, véase Ontología: Hermenéutica de la facticidad. Alianza, Madrid, 1999.

61 Romero, José Luis, “El concepto de vida histórica”, en La vida, p. 19

62 Romero, José Luis, "El concepto de vida histórica”, en La vida, pp. 15-16.

63 Romero, José Luis, "Los conceptos de la cultura: bases para una morfología”, en La vida.

64 Romero, José Luis, "Situaciones e ideologías”, en Situaciones e ideologías en América Latina. Sudamericana, Buenos Aires, 1986, p. 13.

65 Romero, José Luis, “El punto de vista históricocultural”, en La vida, p. 132.

66 Romero, José Luis, "La biografía como tipo historiográfico”, en Sobre la biografía y la historia. Sudamericana, Buenos Aires, 1945, p.34.

67 Romero, José, Luis, La revolución burguesa en el mundo feudal. Sudamericana, Buenos Aires, 1967, pp. 510-511.

68 Romero, José Luis, "La formación de la conciencia contemporánea”, en Introducción al mundo actual. Galatea, Buenos Aires, 1956, p.60.

69 Romero, José Luis, "Introducción al mundo actual”, en Introducción, pp.47-52.

70 Romero, José Luis, El desarrollo de las ideas en la sociedad argentina del siglo XX. Fondo de Cultura Económica, México D.F., 1965, p.7.

71 Romero, José Luis, Breve historia de la Argentina. Huemul, Buenos Aires, 1978, p. 163.

72 Romero, José Luis, Breve historia, p. 102

73 Romero, José Luis, “Experiencia y saber histórico en Alejandro Korn”, en La experiencia argentina y otros ensayos. Belgrano, Buenos Aires, 1980 p. 294.

74 Romero, José Luis, “Prólogo”. En La historia y la vida. Yerba Buena, Buenos Aires, 1945, p. xii

75 En efecto, la militancia socialista de Romero no se deriva de una concepción marxista de la sociedad. Su consideración histórica del saber, más bien, sería un punto común de partida 
desde el cual poco se comparte. En efecto, para Romero la sociedad es un conjunto de personas vinculadas mediante relaciones fundamentadas en principios y normas que le dan estabilidad, estableciendo un sistema de fines comunes a toda la sociedad, el que es expresado por un orden jurídico y político. Cuando las estructuras desde alli erigidas se pierde tal unidad, disgregándose lo social ("Antes de disgregarnos", en La experiencia argentina, p.497). Es claro que ni siquiera las versiones más culturalistas del marxismo podrían partir de tal consideración unitaria de la sociedad y dialógica de su construcción. Por ejemplo, la concepción gramsciana de la crisis orgánica podría pensar tal experiencia de la desunión, pero para volver a una originaria división cuya mediación económica es ausente en tal definición de Romero. Es claro que éstas si aparecen cuando son descritos procesos y grupos sociales. Pero no alcanza el nivel agónico mínimo que puede poseer una teoría para considerarse, a sí, marxista.

76 Romero, José Luis, “Antes de disgregarnos”, en La experiencia, p.496.

Romero, José Luis, “El liberalismo latinoamericano”, en Situaciones, p. 155

78 Romero, José Luis, Latinoamérica: las ciudades y las ideas. Siglo veintiuno editores, Buenos Aires, 1976, p.71.

79 Romero, José Luis, Latinoamérica, p. 143.

80 Romero, José Luis, Latinoamérica, pp. 295-310.

81 Gorelik, Adrián, "Miradas sobre Buenos Aires: Los itinerarios urbanos del pensamiento social", en Miradas sobre Buenos Aires. Historia cultural y crítica urbana. Siglo veintiuno, Buenos Aires, 2004, p.137.

82 Romero, José Luis, "La ciudad latinoamericana y los movimientos políticos”, en Las ideologías de la cultura nacional y otros ensayos, Centro Editor de América Latina, Buenos Aires, 1982.

83 Annino, Antonio "Soberanías en lucha", en Guerra, Francois-Xavier \& Annino, Antonio (Coordinadores), Inventando la nación. Iberoamérica. Siglo XIX, Fondo de Cultura Económica, México D.F., 2003, p. 153

84 Faletto, Enzo ; Kirkwood, Julieta, Sociedad burguesa y liberalismo romántico en el siglo XIX. (Mimeógrafo), 1974, p. 47.

85 Romero, José Luis, “Campo y ciudad: las tensiones entre dos ideologías”, en Las ideologías, p.106.

86 Rama, Ángel, "Fundación de la poesía social: De Hernández a Antonio Lussich”, en La crítica de la cultura en América Latina. Ayacucho, Caracas, 1985.

87 Williams, Raymond, El campo y la ciudad. Paidós, Buenos Aires, 2001.

88 Romero, José Luis, El pensamiento político de la derecha latinoamericana. Paidós, Buenos Aires, 1970, p. 111.

89 Romero, José Luis, “Campo y ciudad: las tensiones entre dos ideologías”, en Las ideologías, p. 114. 
90 Romero, José Luis, “Vida rural y vida urbana, 1810-1880”, en La ciudad occidental. Culturas urbanas en Europa y América. Siglo veintiuno, Buenos Aires, 2009, p.234.

91 Romero, José Luis, "Vida rural y vida urbana, 1810-1880”, en La ciudad occidental, p. 133.

92 Romero, José Luis, “El liberalismo latinoamericano”, en Situaciones, p.168; Romero, José Luis, El pensamiento político,p. 161.

93 Romero, José Luis, El pensamiento político,p. 167.

94 Romero, José Luis, “Universidad y democracia”, en La experiencia argentina, p. 353.

95 Romero, José Luis, “La cultura argentina”, en La experiencia argentina, p. 132.

96 Romero, José Luis, "El estilo de la cultura argentina”, en La experiencia argentina, p.121.

97 Romero, José Luis, “La cultura argentina”, en La experiencia argentina, p. 133.

98 Romero, José Luis, “La cultura argentina”, en La experiencia argentina, p. 136.

99 "Los conceptos de la cultura: bases para una morfología”, en La vida histórica.

\section{BIBLIOGRAFÍA}

Agamben, Giorgio, Homo sacer, Pre-Textos, Valencia, 2003

Ardao, Arturo, Nuestra América Latina, Temas de la Banda Oriental, Montevideo,1986

Arendt, Hanna, La condición humana, Paidós, Buenos Aires, 2005

, Sobre la revolución, Alianza, Madrid, 2004

Arfuch, Leonel (Comp.) Pensar este tiempo: espacios, afectos, pertenencias, Paidós, Buenos Aires, 2005

Aristóteles, Política

Barthes, Rolland, La aventura semiológica, Paidós, Barcelona, 1990

Benjamin, Walter, Diario de Moscú, Madrid, Taurus, 1990

, Dirección Única, Alfaguara, Madrid, 2005

, El libro de los pasajes, Akal, Madrid, 2005

, Infancia en Berlín hacia 1900, Alfaguara, Madrid, 1982

Buck-Morss, Susan, Walter Benjamin, escritor revolucionario, Interzona, Buenos Aires, 2005

Burchard, Johnn \& Handlin, Oscar (Editores), The historian and the city, The MIT and Harvard University Press, Massachussetts, 1963 
Cuesta, Josefina (Editora), Memoria e historia, Marcial Pons, Madrid, 1998

Derrida, Jacques, No escribo sin luz artificial, Cuatro Ediciones, Valladolid, 1999

Descartes, René, Discurso del método, Losada, Buenos Aires, 1959

Duso, Guiseppe (Editor), El contrato social en la filosofía política moderna, Alfonso el Magnánim, Valencia, 1980

Faletto, Enzo \& Kirkwood, Julieta, Sociedad burguesa y liberalismo romántico en el siglo XIX (mimeógrafo), 1974

Ferrater Mora, José, Cuestiones disputadas. Ensayos de filosofía, Revista de Occidente, Madrid, 1955

Freud, Sigmund, Obras Completas. Tomo III, Biblioteca Nueva, Madrid, 1973

Foucault, Michel, Vigilar y castigar, Siglo veintiuno, Buenos Aires, 2002

Fustel de Coulanges, Numa Denis, La ciudad antigua, Madrid, EDAF, 1992

Gorelik, Adrián, Miradas sobre Buenos Aires. Historia cultural y crítica urbana, Siglo veintiuno, Buenos Aires, 2004

Guarda, Gabriel, "Santo Tomás y las fuentes del indianismo urbano". En Boletín de la Academia Chilena de Historia n $^{\circ} 72$ año XXXII, 1965 (Primer Semestre), pp. 5-50

Guerra, Modernidad e independencias. Ensayos sobre las revoluciones hispánicas, Madrid, 1992, Fondo de Cultura Económica

Guerra, Francois-Xavier \& Annino, Antonio (Coordinadores), Inventando la nación. Iberoamérica. Siglo XIX, Fondo de Cultura Económica, México D.F., 2003

Habermas, Jurgen, Historia y crítica de la opinión pública, G G Mass Media, Barcelona, 1991

Hardoy, Jorge \& Morse, Richard, Cultura urbana latinoamericana, CLACSO, Buenos Aires, 1985

Hegel, Georg Willhelm Friedrich, Arquitectura, Kairós, Barcelona, 1981,

Heidegger, Martin, “La falta de nombres sagrados”. En Acento n², pp. 29-32

, Ontología: Hermenéutica de la facticidad, Alianza, Madrid

, Sendas perdidas, Buenos Aires, Losada, 1960

Internacional Situacionista, Textos completos en castellano de la revista. Volumen I: La realización del arte, Literatura Gris, Madrid, 1999

Jaeger, Werner, Paideia: los ideas de la cultura griega, Fondo de Cultura Económica, México D.F., 1942-1945

Jameson, Frederic, El posmodernismo, o, la lógica cultural del capitalismo avanzado, Paidós, Barcelona, 1991 
Janik, Allan \& Toulmin, Saul, La Viena de Wittgenstein, Madrid, Taurus, 1974

Jay, Martin, Campos de fuerza. Entre la historia intelectual y la crítica cultural, Paidós, Buenos Aires, 2003

Lefevbre, Henri, El derecho a la ciudad, Península, Barcelona, 1973

Le Goff, Jacques, Los Intelectuales en la Edad Media, Gedisa, Barcelona, 1996

Lyotard, Jean-Francois, Moralidades posmodernas, Tecnos, Madrid, 1998

Maquiavelo, Nicolás, El Príncipe

Marchant, Patricio, Escritura y temblor, Cuarto Propio, Santiago, 2000

Nancy, Jean-Luc, La creación del mundo o la mundialización, Paidós, Barcelona, 2003

Nietzsche, Friedrich, Así habló Zaratustra, Alianza, Madrid, 1997

Ortega y Gasset, José, Obras Completas. Tomo V, Alianza, Madrid, 1983

Panofsky, Erwin, Arquitectura gótica y escolástica, Buenos Aires, Infinito, 1959

Pocock, John, El momento Maquiavélico: el pensamiento político florentino y la tradición republicana atlántica, Tecnos, Madrid, 2008

Rama, Ángel, La ciudad letrada, Norte, Hanover, 2002 , La crítica de la cultura en América Latina, Ayacucho, Caracas, 1985

Ramos, Julio, Desencuentros de la modernidad en América Latina : literatura y política en el siglo XIX, Cuarto Propio, Santiago, 2003

Romero, José Luis, Breve historia de la Argentina, Huemul, Buenos Aires, 1978

, El desarrollo de las ideas en la sociedad argentina del siglo XX, Fondo de Cultura Económica, México D.F., 1965

, Estudio de la mentalidad burguesa, Madrid, 1987

, Introducción al mundo actual, Galatea, Buenos Aires, 1956

, La ciudad occidental. Culturas urbanas en Europa y América, Siglo veintiuno, Buenos Aires, 2009

, La experiencia argentina y otros ensayos, Belgrano, Buenos Aires, 1980

, La historia y la vida, Yerba Buena, Buenos Aires, 1945

, La revolución burguesa en el mundo feudal, Sudamericana, Buenos Aires, 1967

, La vida histórica, Sudamericana, Buenos Aires, 1988

, Las ideologías de la cultura nacional y otros ensayos, Centro Editor de América Latina, Buenos Aires, 1982, 
, Latinoamérica: las ciudades y las ideas, Siglo veintiuno editores, Buenos Aires, 1976

, Situaciones e ideologías en América Latina, Sudamericana, Buenos Aires, 1986

, Sobre la biografía y la historia, Sudamericana, Buenos Aires, 1945

Sarlo, Beatriz, Una modernidad periférica : : Buenos Aires 1920 y 1930, Nueva Visión, Buenos Aires, 1988

Sennett, Richard, El declive del hombre público, Península, Barcelona, 2002

Simmel, Georg, “La metrópolis y la vida mental”. En Bifurcaciones $n^{\circ} 4$

Stoetzer, Carlos, El pensamiento político en la América española durante el periodo de la emancipación (1789-1925). Volumen I, Instituto de Estudios Políticos, Madrid, 1966

Strauss, Leo, El hombre y la ciudad, Amorrortu, Buenos Aires, 2006

Persecution and the art of writing, Free Press, Illinois, 1952

Taubes, Jacob, Del culto a la cultura. Elementos para una crítica de la razón histórica, Katz, Buenos Aires, 2007

Terán, Oscar, Vida intelectual en el Buenos Aires fin-de-siglo (1880-1910) : derivas de la "cultura científica”, Fondo de Cultura Económica, México D.F., 2000

VVAA, Calle y acontecimiento, FONDART, Santiago, 2001

, De historia e historiadores. Homenaje a José Luis Romero, México D.F., Siglo Veintiuno, 1982

Weber, Max Economía y Sociedad: esbozo de una sociología comprensiva, Fondo de Cultura Económica, México D.F., 1964

Williams, Raymond, El campo y la ciudad, Paidós, Buenos Aires, 2001

Wittgenstein, Ludwig, Investigaciones filosóficas

\section{ACERCA DEL AUTOR}

Alejandro Fielbaum S: Licenciado filosofía por la Pontificia Universidad Católica de Chile, y egresado de Sociología por la misma casa de estudios. Actualmente cursa el Magíster en Estudios Latinoamericanos, en la Universidad de Chile. E-mail: afielbaums@gmail.com 